\title{
Heat and Mass Transfer in the Reduction of Iron Oxide Pellet with Hydrogen*
}

\author{
By Reijiro TAKAHASHI,** Jun-ichiro YAGI,** and Yasuo OMORI**
}

\section{Synopsis}

The reduction curve and the change of surface temperature of an iron oxide pellet were determined during the reduction with hydrogen in temperature range of $800^{\circ}$ to $1100^{\circ} \mathrm{C}$. The surface temperature was measured by using an automatic optical pyrometer. Further, a mathematical model for a nonisothermal reaction was derived on the basis of the unreacted core model, in which heat and mass transfer are considered.

The observed values of fractional reduction and surface temperature of the pellet were compared with the theoretical values estimated by this model. The reduction curves and the surface temperatures obtained from this model were almost coincided with the observed values.

The temperature drop observed during the reduction process was not so large, because the heat transfer by radiation played a predominant role in heat transfer from the surroundings to the surface of pellet under the conditions of the present experiment. Therefore, the rate parameters in the rate equation have been determined with a sufficient accuracy by analysing the measured values on an assumption that the reaction would proceed isothermally.

\section{Introduction}

In kinetic studies on gaseous reduction of iron oxide, many investigators ${ }^{1-7)}$ have attempted to obtain the reaction rate on the assumption of some rate-controlling step under the isothermal condition. However, the reaction would proceed nonisothermally due to the heat of reaction. Strictly speaking, the gassolid noncatalytic reaction should be analysed as the nonisothermal reaction. Recently, some attempts were made to investigate the reaction mechanism under the nonisothermal condition and also to observe the temperature change caused by the heat of reaction, by inserting a thermocouple into an iron oxide pellet. For instance, Strangway et al. ${ }^{8)}$ measured temperature change of the pellet in hydrogen reduction at $860^{\circ} \mathrm{C}$. As a result, the maximum temperature drop during reduction was found to be $21^{\circ} \mathrm{C}$. Further, the drop measured by Kondo et al. ${ }^{9)}$ was about $100^{\circ} \mathrm{C}$ in the hydrogen reduction at $1000^{\circ} \mathrm{C}$. While, for elucidating the mechanism of the noncatalytic reaction such as the gaseous reduction of iron oxide, J. Shen and J. M. Smith ${ }^{10}$ and A. K. Lahiri ${ }^{11)}$ investigated theoretically the rate of reaction on the basis of the unreacted core model taking the heat and mass transfer into account. In their papers, however, the temperature change measured by inserting thermocouple into a pellet seems not very much precise and the measured values were not simulated by a mathematical model.

In general, for analysing noncatalytic reaction between gas and solid, it is necessary to measure experimentally the temperature changes of the solid caused by the reaction, and it is also necessary to estimate theoretically the temperature changes and fractional conversion of the solid based on a mathematical model during the course of reaction. In view of this point, the authors measured the fractional reduction of an iron oxide pellet with hydrogen in the temperature range of $800^{\circ}$ to $1100^{\circ} \mathrm{C}$ and the surface temperature of pellet was also measured by an automatic optical pyrometer. The measured values were compared with those calculated from a nonisothermal model in which the heat and mass transfer are taken into account.

\section{Experiment}

\section{Sample}

Fluxed pellet supplied by Kobe Steel, Ltd. having 1.35 basicity (defined by $\mathrm{wt}^{\%} / \mathrm{CaO} / \mathrm{wt}^{\circ} / \mathrm{SiO}_{2}$ ) was used as the sample. The sample pellet had porosity of $0.19 \pm 0.005$, apparent density of $3.83 \mathrm{~g} / \mathrm{cm}^{3}$, and size of approximately $1.2 \mathrm{~cm}$ in diameter. Cracking and swelling during the reduction were scarcely found in the pellet. Chemical composition of the pellet is given in Table 1.

\section{Experimental Apparatus and Procedure}

The experimental apparatus is shown in Fig. 1. The reaction tube used had an inside diameter of $7.7 \mathrm{~cm}$, made of heat-resisting steel, No. 42, as specified in Japanese Industrial Standard. This tube was installed in an electric furnace equipped with $\mathrm{SiC}$ heating elements. The electric furnace was of a veritical type, about $120 \mathrm{~cm}$ in hight and capable of splitting into 2 parts vertically. Heating was made in three different stages by the delta connecting method. High purity hydrogen gas in a cylinder was introduced into the reaction tube through automatic regulating gages. The lower portion of the reaction tube was filled with alumina balls and the gas was pre-heated to prevent the temperature drop within the tube. In the reaction tube, a pellet was suspended with a platinum wire connected to a quartz spring (with a maximum load $7 \mathrm{~g}$ and sensitivity $10 \mathrm{mg}$ ). The movement of the end of the quartz spring during the reduction was measured

Table 1. Chemical composition of the pellet

\begin{tabular}{c|ccccccc} 
Component & $\mathrm{T} \cdot \mathrm{Fe}$ & $\mathrm{FeO}$ & $\mathrm{SiO}_{2}$ & $\mathrm{CaO}$ & $\mathrm{Al}_{2} \mathrm{O}_{3}$ & $\mathrm{MgO}$ & $\mathrm{S}$ \\
\hline wt $\%$ & 62.55 & 1.08 & 3.66 & 4.94 & 1.19 & 0.48 & 0.023
\end{tabular}

* Originally published in Bull. Res. Inst. Min. Dress. Met., Tohoku Univ., 27 (1971), 175, in Japanese. English version received June 9, 1973.

** The Research Institute of Mineral Dressing and Metallurgy, Tohoku University, Katahira, Sendai 980. 
by a cathetometer. The change in surface temperature of the pellet was measured by an automaticallyoperated optical pyrometer attached to the top of reaction tube.

Because it was difficult to measure simultaneously the surface temperature and weight change, these measurements were carried out using duplicate and separate experiment. The surface temperature was measured in the following manner; the quartz spring was removed from the platinum wire and an alumina ball was hanged from the pellet in order to avoid swinging of the pellet. Then, the surface temperature of the pellet fixed in the reaction tube was measured by the optical pyrometer with the aid of a mirror. The output of the pyrometer at a initial temperature was adjusted to zero with the aid of a D.C. potentiometer, and then, the temperature changes during reduction were recorded after amplifying deviation from the initial temperature.

In order to check the effect of the gaseous atmosphere on the transmissivity between the pellet and the pyrometer, an alumina ball was suspended with the platinum wire at a given temperature, and the

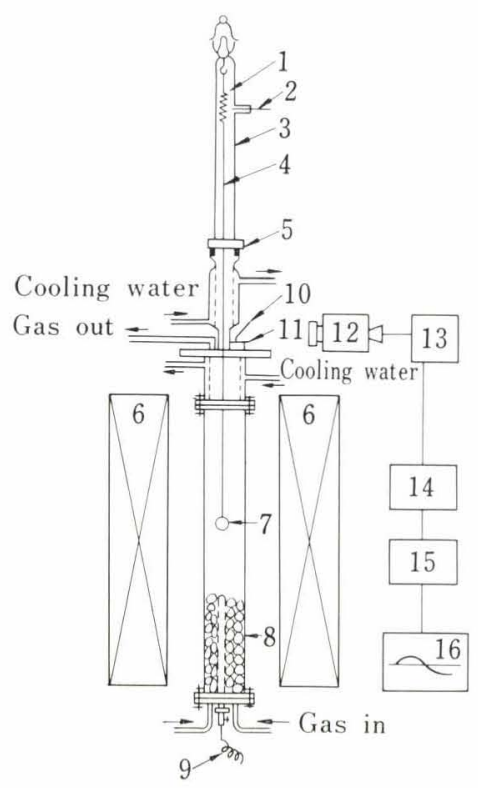
1. Spring balance
9. Thermocouple
2. Thermometer
10. Mirror
3. Glass tube
4. Pt-wire
5. O-ring seal
11. Quartz spring
Electric furnace
. Sample
Alumina balls
Optical pyrometer
13. $\mathrm{mV}$ converter
14. D. C. Potentiometer
15. Amplifier
16. Recorder

Fig. 1. Experimental apparatus

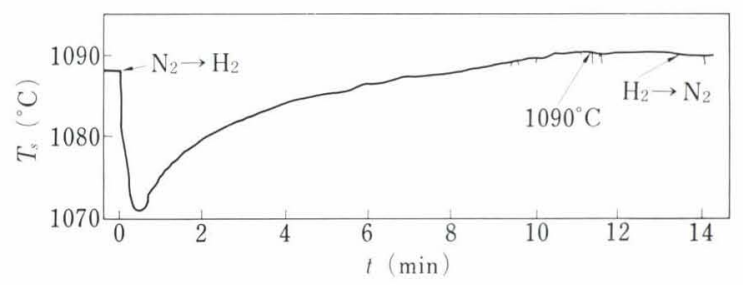

Fig. 2. Observed temperature change on the surface of the pellet $\left(T_{b}=1090^{\circ} \mathrm{C}, p_{\mathrm{H}_{2}}=1.0 \mathrm{~atm}, V=30 \mathrm{~N} l / \mathrm{min}\right.$, $d_{p}=1.2 \mathrm{~cm}, \varepsilon_{p}=0.185$ ) surface temperature changes of the ball in the streams of nitrogen as well as hydrogen were measured in the same way as mentioned above. Almost same temperature changes were obtained in both of the gases. Furthermore, the concentration of water vapour produced by the reaction was extremely low under these experimental conditions. Thus, the effect of the gaseous atmosphere on the transmissivity could be neglected. On the other hand, since the emissivity of the reduced pellet was not accurately known, the surface temperature of the completely reduced pellet measured by the pyrometer was taken equal to the gaseous temperature measured by $\mathrm{Pt} / \mathrm{PtRh}(13 \%)$ thermocouple, which was inserted into the reaction tube.

An example of the observed temperature change on the surface of the pellet was shown in Fig. 2. The apparent temperature at the end of reduction was slightly different from that at the beginning of a run. It seems that this difference may be caused by the change in emissivity of the pellet surface due to the formation of metallic iron. In this study, the output of the pyrometer at the end of reduction was used as the starting temperature. Moreover, in measuring the surface temperature of the pellet, readings of optical pyrometer indicated the emissivity of the pellet surface would include that of the platinum wire which supporting the pellet. As the area occupied by the platinum wire, however, is negligibly small in comparison with that of the pellet, it may scarcely cause the measurement error.

\section{Mathematical Model for Gas-Solid Reaction under Nonisothermal Condition}

The nonisothermal reaction model given below may be derived, on the assumption that the reaction expressed by Eq. (1) may proceed according to the unreacted-core model ${ }^{3)}$ shown in Fig. 3, and that each process of heat and mass transfer including chemical reaction may occur steadily and successively. ${ }^{10,11}$

$$
(1 / 3) \mathrm{Fe}_{2} \mathrm{O}_{3}+\mathrm{H}_{2}=(2 / 3) \mathrm{Fe}+\mathrm{H}_{2} \mathrm{O}
$$

(1) Mass transfer processes:

The rate of diffusion process through gaseous film;

$$
R^{*}=4 \pi r_{o}^{2} k_{f}\left(C_{b}-C_{s}\right) \ldots
$$

The rate of intraparticle diffusion process;

$$
R^{*}=4 \pi r_{o} r_{i} D_{s}\left(C_{s}-C_{i}\right) /\left(r_{o}-r_{i}\right) \ldots
$$

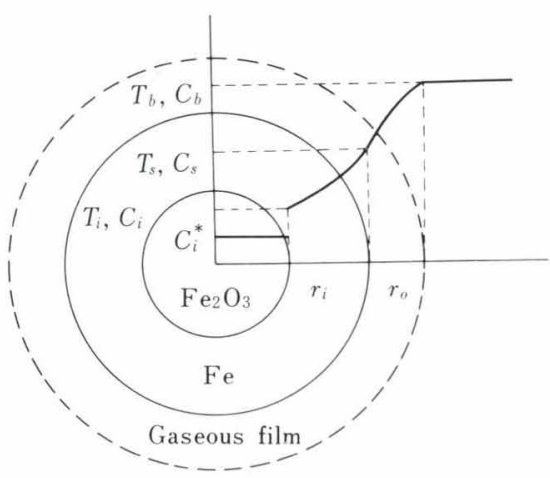

Fig. 3. Unreacted core model for nonisothermal reaction 
The rate of chemical reaction process;

$$
R^{*}=4 \pi r_{i}^{2} k_{i}(1+1 / K)\left(C_{i}-C_{i}^{*}\right) \ldots
$$

From Eqs. (2) to (4), the concentrations of $\mathrm{H}_{2}$ at the reaction interface and at the pellet surface can be expressed by Eqs. (5) and (6), respectively:

$$
\begin{array}{r}
\left(C_{i}-C_{i}^{*}\right) / C_{b}=\left(1-C_{i} / C_{b}\right) /\left[1+F_{o} \exp \left\{\left(E / R T_{b}\right)\right.\right. \\
\left.\left.\times\left(1-\mathcal{T}_{b} / \mathcal{T}_{i}\right)\right\}\right] \ldots \ldots \ldots \ldots \ldots \ldots \ldots \ldots \ldots \ldots \ldots \ldots \ldots \\
C_{s}=\left\{C_{b}\left(1-r_{i} / r_{o}\right)+\beta\left(r_{i} / r_{o}\right) C_{i}\right\} /\left\{1-r_{i} / r_{0}+\beta\left(r_{i} / r_{o}\right)\right\} . .
\end{array}
$$
where,

$$
\begin{aligned}
F_{o} & \equiv\left(r_{i} / r_{o}\right)^{2} \alpha \delta\left\{\beta+\left(1-r_{i} / r_{o}\right) /\left(r_{i} / r_{o}\right)\right\} ; \\
\alpha & \equiv k_{b} r_{o} / D_{s} ; \quad \beta \equiv D_{s} / r_{o} k_{f} ; \quad \delta \equiv 1+1 / \hbar .
\end{aligned}
$$

(2) Heat transfer processes:

The rate of heat transfer between the surface of a pellet and surroundings;

$$
R_{h}^{*}=4 \pi r_{o}^{2} h\left(T_{b}-T_{s}\right)
$$

The rate of heat conduction through the porous reduced layer;

$$
R_{h}^{*}=4 \pi r_{o} r_{i} k_{s}\left(\mathcal{T}_{s}-\mathcal{T}_{i}\right) /\left(r_{o}-r_{i}\right) .
$$

The rate of heat absorption caused by chemical reaction;

$$
\begin{aligned}
R_{h}^{*}= & 4 \pi r_{i}^{2}\left(-\Delta H_{T_{i}}^{\circ}\right) k_{o} \exp \left(-E / R T_{i}\right) \\
& \times(1+1 / K)\left(C_{i}-C_{i}^{*}\right) \ldots \ldots \ldots \ldots \ldots
\end{aligned}
$$

From Eqs. (7) to (9), temperatures at the reaction interface and pellet surface can be expressed by Eqs. (10) and (11), respectively;

$$
\begin{aligned}
\left(T_{b}-T_{i}\right) / T_{b}=\phi \alpha\left\{\left(C_{i}-C_{i}^{*}\right) /\left(C_{b}-C_{b}^{*}\right)\right\} \\
\times \exp \left\{E\left(1-T_{b} / T_{i}\right) / R T_{b}\right\}\left(r_{i} / r_{0}\right)^{2} \\
\quad \times\left\{\zeta+\left(1-r_{i} / r_{o}\right) /\left(r_{i} / r_{o}\right)\right\} \quad \ldots \ldots \ldots \ldots \ldots \ldots \ldots \ldots \ldots \ldots \ldots \ldots \ldots \ldots \\
T_{s}=\left\{T_{b}\left(1-r_{i} / r_{o}\right)+\zeta\left(r_{i} / r_{o}\right) T_{i}\right\} /\left\{1-r_{i} / r_{o}+\zeta\left(r_{i} / r_{o}\right)\right\} \ldots
\end{aligned}
$$

where,

$$
\phi \equiv\left(C_{b}-C_{b}^{*}\right)\left(-\Delta H_{T_{i}}^{\circ}\right) D_{s} /\left(T_{b} k_{s}\right) ; \quad \zeta \equiv k_{s} /\left(r_{o} h\right) .
$$

For the reaction given by Eq. (1), the following relationship between the dimensionless radius of unreacted core, $r_{i} / r_{o}$, and the dimensionless time, $\theta$, is obtained;

$$
\begin{aligned}
\theta= & M_{h} k_{b}\left(C_{b}-C_{b}^{*}\right) t /\left(3 \rho_{h} r_{o}\right) \\
= & -\int_{1}^{r_{i} / r_{o}} d\left(r_{i} / r_{o}\right) /\left[\left(C_{i}-C_{i}^{*}\right) /\left(C_{b}-C_{b}^{*}\right)\right. \\
& \left.\times \exp \left\{E\left(1-T_{b} / T_{i}\right) / R T_{b}\right\}\right] \quad \ldots \ldots . . .
\end{aligned}
$$

Changes of $C_{i}, T_{i}$, and $f$ with time can be obtained by solving Eqs. (5), (10), and (12) simultaneously. In addition, values of $T_{s}$ and $C_{s}$ can be estimated from Eqs. (6) and (11).

The numerical calculation was conducted in accordance with the Simpson's integration rule by the digital computer of Model 500 in NEAC 2200 series (installed in Tohoku University). In the numerical integration, $r_{o} / 2000$ was chosen as the finite difference for length in radial direction. This finite difference gave a stable solution and required only one minute of computing time for $30 \mathrm{~min}$ of the actual reduction time.

\section{Evaluation of Rate Parameters}

Overall reaction rate of nonisothermal reaction derived as above includes five rate parameters, $k_{f}, k_{i}, D_{s}$, $h, k_{s}$, and heat of reaction $\Delta H_{T_{i}}^{\circ}$. Therefore, these values have to be obtained in order to examine whether or not the overall reaction rate can explain both the measured values of reduction curve and the temperature changes caused by the heat of reaction. In this paper, these rate parameters and heat of reaction were determined by using the experimental conditions, measured values and theoretical equations as will be described hereunder.

\section{Rate Parameters for Mass Transfer}

Since the temperature drop at the reaction interface during reduction was not so significant, as will be explained later, the rate parameters for mass transfer, $k_{f}, k_{i}$, and $D_{s}$, were determined according to the rate analysis of isothermal reaction as given below.

Mass transfer coefficient through gaseous film, $k_{f}$, was estimated by Eq. (13) which had been proposed by W. E. Ranz and W. R. Marshall. ${ }^{12}$ In Eq. (13), diffusion coefficient of reducing gas, $D$, was estimated from Andrussow's equation, ${ }^{13}$ ) while the viscosity of gaseous mixture, $\mu$, was predicted from Wilke's equation, ${ }^{14}$ ) applying the values for respective components calculated from Licht-Stechert's equation. ${ }^{15}$

$$
S h=2.0+0.6 R e_{p}^{1 / 2} \cdot S c^{1 / 3}
$$

For determining the reaction rate constant, $k_{i}$, the measured values are applied to the reaction analysis by the method of mixed control, which should be essentially used for the isothermal reaction. Because the temperature change of reaction interface was not so significant during the hydrogen reduction of iron oxide pellet, the value of $k_{i}$ might be obtained from the rate analysis of isothermal reaction which was assumed to proceed at the starting temperature of a run.

Figure 4 gives the graphical presentation of the measured values. The experimental data shown in Fig. 4 were obtained in the reduction of the fluxed pellet with pure hydrogen at various temperatures, and were plotted according to the method of mixed control. The chemical composition of the fluxed pellet is shown in Table 1. In Fig. 4, the measured values at a higher temperature showed a relatively good linearity, while those at a lower temperature tend to deviate from the linearlity. The lines in Fig. 4 were drawn by fitting straight lines to the data with fractional reduction over 0.3 . The measured values in the reduction with hydrogen diluted with nitrogen and at $1023^{\circ} \mathrm{C}$ are also shown in Fig. 4. The details will be described later. The reaction rate constant, $k_{b}$, was determined from the value of $\left(t-t_{f}\right) / F$ at $3 F-$ $2 F^{2}=0$ in Fig. 4 and $\log k_{b}$ are plotted $v s .1 / T_{b}$ in Fig. 5. From Fig. 5, the temperature dependence of $k_{b}$ was expressed by Eq. (14), and the activation energy was in the same magnitude of order for the acid pellet mentioned in the authors' previous report. ${ }^{3}$ ) 


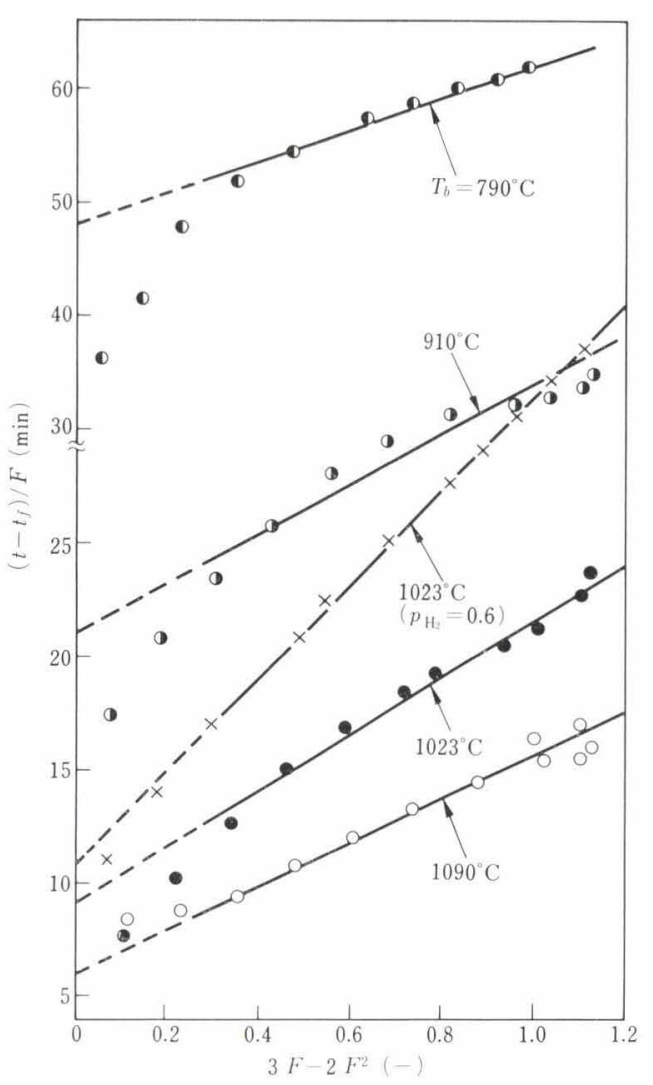

Fig. 4. Plots of the experimental values at various temperature by $\left(t-t_{f}\right) / F$ vs. $3 F-2 F^{2} \quad\left(p_{\mathrm{H}_{2}}=1.0 \mathrm{~atm}\right.$, $\left.V=30 \mathrm{Nl} / \mathrm{min}, d_{p}=1.2 \mathrm{~cm}\right)$

Because the Eq. (14) was used for $k_{i}$ in Eq. (4) in the numerical evaluation, $k_{b}$ and $T_{b}$ were replaced by $k_{i}$ and $T_{i}$ respectively.

$$
k_{i}=\exp \left(14.83-22.5 \times 10^{3} / R T_{i}\right)
$$

Equilibrium constant, $K$, was calculated from Eq. (15) obtained from the thermodynamic data ${ }^{16}$ of wustite-iron-hydrogen-water vapour equilibrium.

$$
K=\exp \left(1.08-1740 / T_{i}\right)
$$

Intraparticle diffusivity, $D_{s}$, was theoretically estimated from Eq. (16). In this equation, the porosity of reduced iron layer, $\varepsilon_{f}$, is related to that of the original unreacted pellet, $\varepsilon_{p}$, as presented by Eq. (17), ${ }^{17}$ with the assumption that the particle size of the pellet during the reduction does not change. For the acid pellet used in the authors' previous report, ${ }^{3)}$ Eq. (18) advocated by the authors on the basis of experimental data reported by R. G. Olsson and W. R. McKewan ${ }^{18)}$ and Y. Hara et al. ${ }^{19}$ ) was adopted as the temperature dependence of labyrinth factor, $\xi$. For the fluxed pellet used in the present experiment, the value of $\xi$ was calculated from the value of $D_{s}$ (see Fig. 4) obtained by the analysis according to the method of the mixed control. The results obtained are given in Fig. 6 . As is clear from this figure, the value of $\xi$ is nearly equal to 0.2 for the fluxed pellet and does not have a temperature dependence. The value 0.2 was used in order to estimate the overall reaction rate for the theoretical reproduction of the reduction curves. The labyrinth factor for the reduction with hydrogen

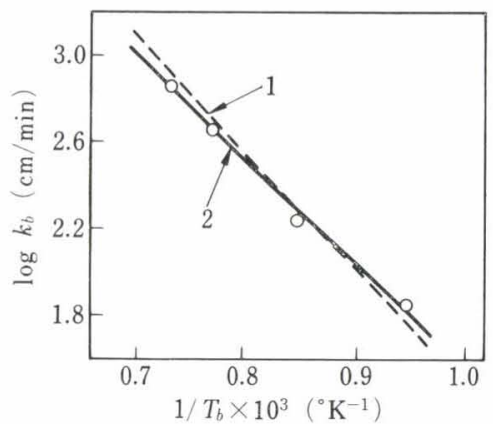

Fig. 5. Temperature dependence of the reaction rate constant

1: $\quad k_{b}=\exp \left(16.2-25.7 \times 10^{3} / R T_{b}\right),{ }^{3)}$ (Acid pellet)

2: Eq. (14), (fluxed pellet)

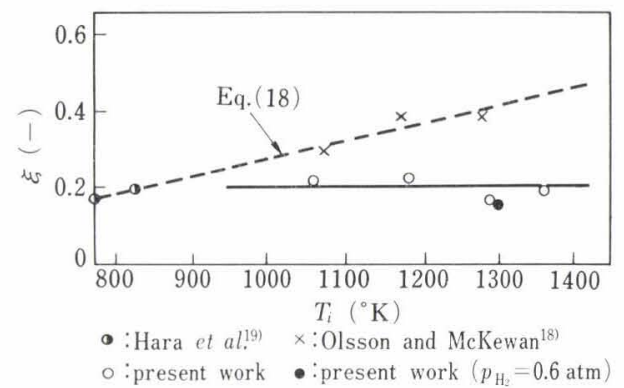

Fig. 6. Relationship between labyrinth factor and reducing temperature

diluted with nitrogen and at $1023^{\circ} \mathrm{C}$ (see Fig. 4) is also shown in Fig. 6. The value in this case was also about 0.2. It was found from the present results that the change in the concentration of reducing gas did not affect the value of $\xi$.

$$
\begin{aligned}
D_{s} & =\varepsilon_{f} \cdot \xi \cdot D \quad \ldots \ldots \ldots \ldots \ldots \ldots \ldots \ldots \ldots \ldots \ldots \ldots \ldots \ldots \ldots \ldots \ldots \ldots \ldots \ldots \\
\varepsilon_{f} & =0.534+0.466 \varepsilon_{p} \ldots \ldots \ldots \ldots \ldots \ldots \\
\xi & =4.4 \times 10^{-4}\left(T_{i}-773\right)+0.18 \\
& \left(T_{i} \geqq 773^{\circ} \mathrm{K}\right) \ldots
\end{aligned}
$$

\section{Rate Parameters for Heat Transfer}

In the gas-solid reaction, temperature change at the reaction interface may occur more or less. Therefore, both the heat transfer between the surroundings and the surface of a pellet, and conduction through reduced iron layer should be considered in the rate analysis of the reaction. Moreover, in the heat transfer process, radiant heat transfer may play an important role to the overall heat transfer rate, especially at high temperature. In this study, the rate parameter for heat transfer, $h$ and $k_{s}$, were determined by taking into account both convective and radiant heat transfer between surroundings and the pellet surface, and conduction alone through the reduced iron layer.

Thermal conductivity of the reduced iron layer, $k_{s}$, was estimated by Eq. (19), including the effect of porosity. In Eq. (19), thermal conductivity of pure iron, $k_{\mathrm{Fe}}$, depends on temperature. Therefore, the temperature dependence of $k_{\mathrm{Fe}}$ was represented by Eq. (20) on the basis of the observed data. ${ }^{20)}$ In the cases of a poor thermal conductivity of sample, the large porosity of reduced iron layer and the high re- 
ducing temperature, the radiant heat transfer in the pores of the solid must also be considered. ${ }^{21,22}$ It was, however, assumed here that the conductive heat transfer was predominant within a solid substance.

$$
\begin{aligned}
k_{s}= & \left(1-\varepsilon_{f}\right) k_{\mathrm{Fe}} \ldots \ldots \ldots \ldots \ldots \ldots \ldots \ldots \ldots \ldots \ldots \ldots \ldots \ldots \ldots \ldots \ldots \ldots \ldots \ldots \ldots \ldots \ldots \ldots \ldots \ldots \ldots \ldots \ldots \ldots \ldots \\
k_{\mathrm{Fe}}= & 10.80-1.074 \times 10^{-2} T_{i}+3.858 \times 10^{-6} T_{i}^{2} \\
& -8.35 \times 10^{-10} T_{i}^{3} \ldots \ldots \ldots \ldots \ldots \ldots \ldots \ldots
\end{aligned}
$$

Taking into account the convection and radiation, the heat transfer coefficient between the surroundings and the surface of a pellet, $h$, was defined by Eq. (21). Coefficient of convective heat transfer, $h_{c}$, was estimated from Eq. (22), ${ }^{12}$ while that of radiant heat transfer, $h_{r}$, was calculated by Eq. (23). ${ }^{23}$ )

$$
\begin{aligned}
h & =h_{c}+h_{r} \ldots \ldots \ldots \ldots \ldots \ldots \ldots \ldots \ldots \ldots \ldots \ldots \ldots \ldots \ldots \ldots \ldots \ldots \ldots \ldots \ldots \ldots \ldots \ldots \ldots \ldots \\
\mathcal{N} u & =2.0+0.6 \operatorname{Re}_{p}^{1 / 2} \operatorname{Pr}^{1 / 3} \quad \ldots \ldots \ldots \ldots \ldots \ldots \\
h_{r} & =8.133 \phi_{s t}\left(T_{b}+T_{s}\right)\left(T_{b}^{2}+T_{s}^{2}\right) \times 10^{-11}
\end{aligned}
$$

where,

$$
\dot{\phi}_{s \ell}=\varepsilon_{s} \cdot \varepsilon_{\imath} /\left\{\varepsilon_{\ell}+\left(d_{p} / D_{\ell}\right)^{2} \varepsilon_{s}\left(1-\varepsilon_{\ell}\right)\right\}
$$

For evaluating the ' $h$ ' by using Eqs. (21) to (23), it was necessary to determine the appropriate value of the emissivity. However, the emissivity reported by different researchers scattered very widely. In this paper, the value of $\varepsilon_{s}$ was estimated from the comparison of the measured surface temperature of a pellet with the calculated ones for arbitrary values of $\varepsilon_{s}$ on the basis of the nonisothermal model which includes $\varepsilon_{s}$ as the parameter. As the result, the most probable emissivity of the pellet was found to be 0.5. In the calculation for determining the value of $\varepsilon_{s}$, the value of $\phi_{s t}$ in Eq. (23) is affected by the reaction apparatus and reaction condition, and $\varepsilon_{s}$ is not exactly equal to $\varepsilon_{t}$. However, the value of $\phi_{s t}$ did not change so significantly, because the values of $\varepsilon_{s}$ were close to that of $\varepsilon_{t}$. The calculation was made under the condition $\varepsilon_{s}=\varepsilon_{t}$ in this paper.

\section{Temperature Dependence of Heat of Reaction}

The heat of reaction, $\Delta H_{T_{i}}^{\circ}$, would change with temperature change at the reaction interface during reduction. The change in the heat of reaction can not be neglected when temperature difference is noticeable between reaction interface and bulk gas. In the present study, the following relations between heat of reaction for the reaction given by Eq. (1) and temperature were obtained from the thermodynamic data, ${ }^{24)}$ and were incorporated into the mathematical model.

$$
\begin{aligned}
\Delta H_{T_{i}}^{\circ}= & 0.0447 \times 10^{-5} T_{i}^{3}-0.895 \times 10^{-3} T_{i}^{2} \\
& -3.97 T_{i}-1.411 \times 10^{5} / T_{i}+9323 \\
& \left(T_{i} \leqq 1041^{\circ} \mathrm{K}\right) \ldots \ldots \ldots \ldots \\
\Delta H_{T_{i}}^{\circ}= & 0.0447 \times 10^{-5} T_{i}^{3}-1.895 \times 10^{-3} T_{i}^{2} \\
& -2.64 T_{i}-1.411 \times 10^{5} / T_{i}+9473 \\
& \left(1041 \leqq T_{i} \leqq 1179^{\circ} \mathrm{K}\right) \\
\Delta H_{T_{i}}^{\circ}= & 0.0447 \times 10^{-5} T_{i}^{3}-3.015 \times 10^{-3} T_{i}^{2} \\
& -1.12 T_{i}-1.411 \times 10^{5} / T_{i}+9384 \\
& \left(T_{i}>1179^{\circ} \mathrm{K}\right) \ldots \ldots \ldots \ldots
\end{aligned}
$$
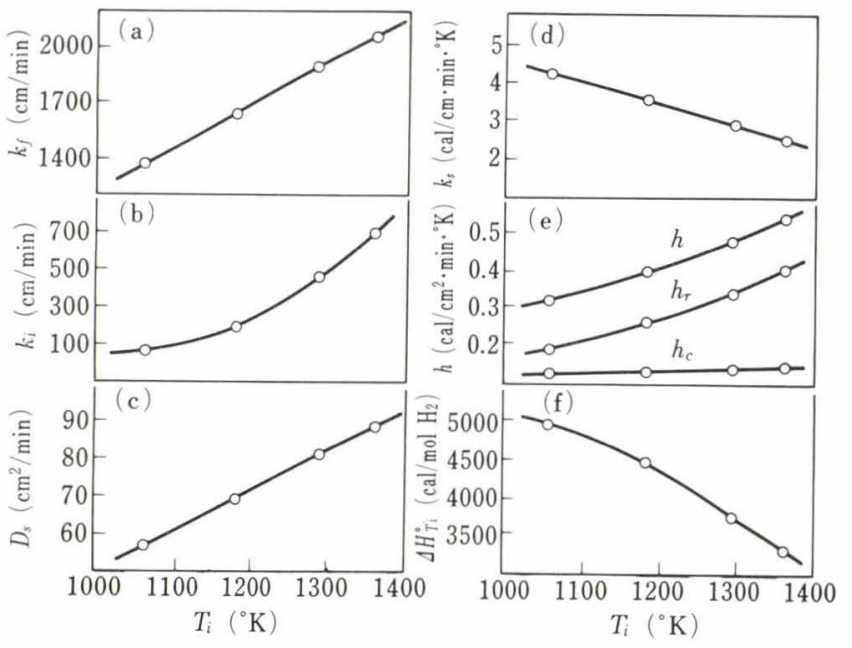

Fig. 7. Temperature dependences of the rate parameters

The heat of the reaction can be obtained from the equations to be 7.6 and $3.9 \mathrm{kcal} / \mathrm{mol} \mathrm{H}_{2}$ at $25^{\circ}$ and $1000^{\circ} \mathrm{C}$, respectively.

\section{Temperature Dependence of Rate Parameters}

The temperature dependences of the rate parameters obtained from the method mentioned above are shown in Fig. 7 for the purpose of mutual comparison. The rate parameters for mass transfer in Fig. 7 (a), (b), and (c) increased with the rise in temperature. While, in the rate parameters for heat transfer in Fig. 7 (d), (e), and (f), the values of $k_{s}$ and $\Delta H_{T_{i}}^{\circ}$ decreased and that of ' $h$ ' increased with the rise in temperature. It was found, in Fig. 7 (e), that the increase in $h_{r}$ was more rapid than that in $h_{c}$ with the rise of temperature. These phenomena suggest that the radiant heat transfer played an important role in the heat transfer at high temperature region.

\section{Heat and Mass Transfer between Surround- ings and Pellet Surface, and in Pellet}

In order to deduce the rate controlling steps for heat and mass transfer, distributions of the hydrogen concentration and the temperature between pellet surface and reaction interface were calculated by using the rate parameters obtained by the method mentioned in the preceding section.

Figure 8 shows distribution of the hydrogen concentration within a pellet with the fractional reduction taken as the parameter. According to this figure, the hydrogen concentration decreased even in the gaseous film at the initial stage of reaction. As the reaction further proceeds, the concentration decreased rapidly within the pellet and its difference between the pellet surface and the reaction interface became more remarkable. In addition, the hydrogen concentration reached a minimum value at the position of $1 / 2$ radius of the pellet. This fact indicates that, in the present reaction system, the resistance of intraparticle diffusion governed the mass transfer process together with the resistance of the chemical reaction.

Temperature distribution in the pellet is shown in Fig. 9. As is clear from this figure, a large temperature drop occurred between the surroundings and the 
pellet surface, while the change of temperature was very slight in the pellet. As a result, there is only a slight temperature difference between the pellet surface and the reaction interface. These results mean

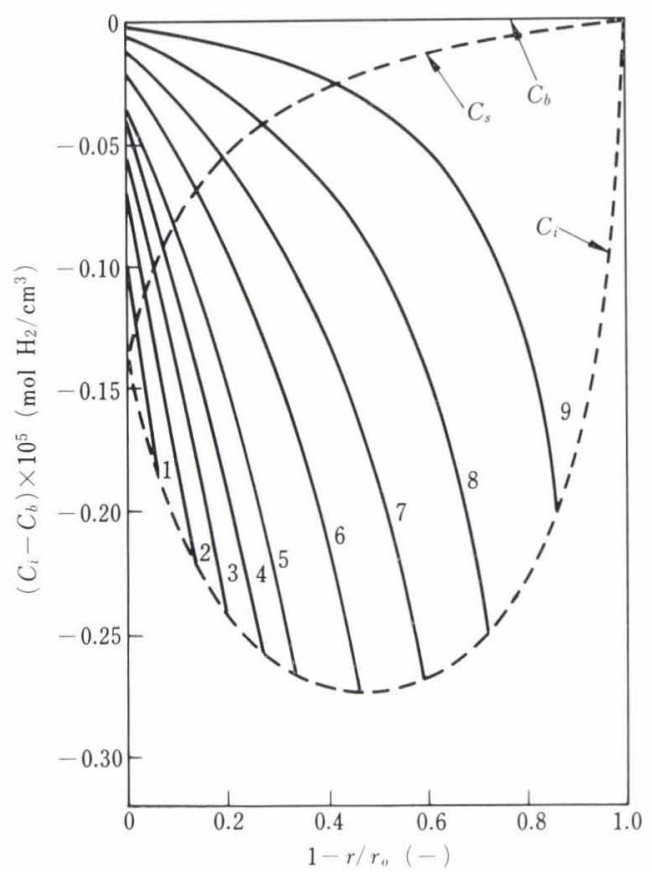

Fig. 8. Distribution of $\mathrm{H}_{2}$ concentration between the surface of the pellet and the reaction interface $\left(T_{b}=\right.$ $1023^{\circ} \mathrm{C}, p_{\mathrm{H}_{2}}=1.0 \mathrm{~atm}, V=30 \mathrm{~N} l / \mathrm{min}, d_{p}=1.2 \mathrm{~cm}$, $\left.\varepsilon_{s}=0.5\right),\left(C_{b}=0.94 \times 10^{-5}, C^{*}=0.53 \times 10^{-5} \mathrm{~mol}\right.$ $\left.\mathrm{H}_{2} / \mathrm{cm}^{3}\right)$

Fractional reduction $(f)$
1: 0.185
2: 0.346
3: 0.484
4: 0.601
5: 0.699
6: 0.849
7: 0.933
8: 0.979
9: 0.997

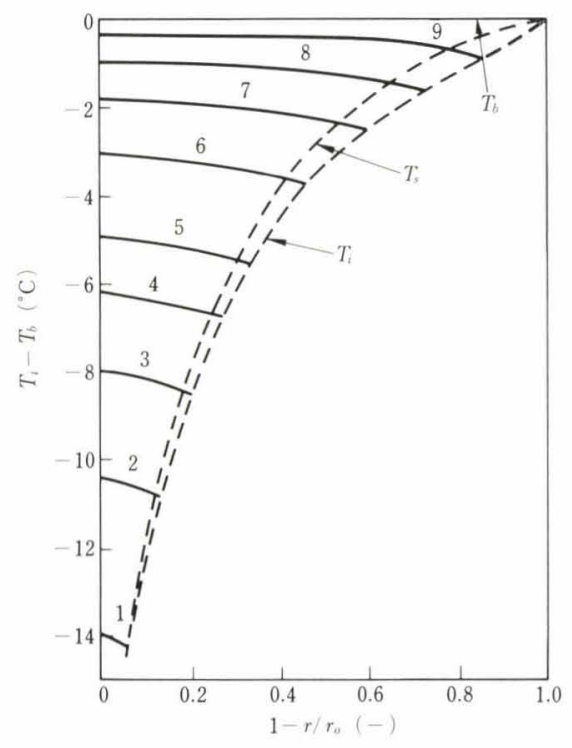

Fig. 9. Distribution of temperature between the surface of the pellet and the reaction interface $\left(T_{b}=\right.$ $1023^{\circ} \mathrm{C}, p_{\mathrm{H}_{2}}=1.0 \mathrm{~atm}, V=30 \mathrm{Nl} / \mathrm{min}, d_{p}=1.2 \mathrm{~cm}$, $\varepsilon_{s}=0.5$ )

Fractional reduction $(f)$
$1: 0.185$
2: 0.396
3: 0.48
4: 0.601
5: 0.699
6: $\quad 0.849$
7: 0.933
8: 0.974
9: $\quad 0.997$

that the thermal conductivity in the reduced iron layer was substantially higher than the heat transfer between the surroundings and the pellet surface, in other words, the heat transfer resistance between the surroundings and the pellet surface governed the overall heat transfer process.

\section{Reduction Curves and Temperature Change on the Surface of Pellet}

Both calculated and measured changes in the fractional reduction and in the surface temperature of a pellet with the progress of the reaction are presented in this section.

The temperature change on the pellet surface at the bulk gas temperature $1023^{\circ} \mathrm{C}$ is shown in Fig. 10 . The measured maximum temperature drop and the pattern of the temperature change on the pellet surface agreed well with the calculated ones obtained from the nonisothermal model, including the radiant heat transfer. The maximum temperature drop was observed somewhat later from the starting point of the reduction, while the speed of recovering to the initial temperature was somewhat faster in the measured curve than in the calculated curve. This difference between the measured and the calculated curves might be caused by the time loss associated with replacing nitrogen with hydrogen in setting-up the reducing conditions and by the reduction of hematite proceeding through the series $\mathrm{Fe}_{2} \mathrm{O}_{3}-\mathrm{Fe}_{3} \mathrm{O}_{4}-\mathrm{FeO}-\mathrm{Fe}$ in the experiment. The time loss was not included in this model, and the heat of reaction for only the $\mathrm{Fe}_{2} \mathrm{O}_{3}-\mathrm{Fe}$ stage was used in this calculation. The calculated curve neglecting the radiant heat transfer is also given in Fig. 10. The curve showed a remarkable deviation from the measured curve. However, the calculated curve including the radiant heat transfer coincided well with the measured curve. Thus, the radiant heat transfer played one of the most important roles in the reducing apparatus and experimental conditions used for this study.

Figure 11 shows a comparison between the measured and the calculated reduction curves under the same reducing conditions as Fig. 10. The calculated curve based on the nonisothermal model including the radiant heat transfer in the overall heat transfer showed a good agreement with the measured values. The

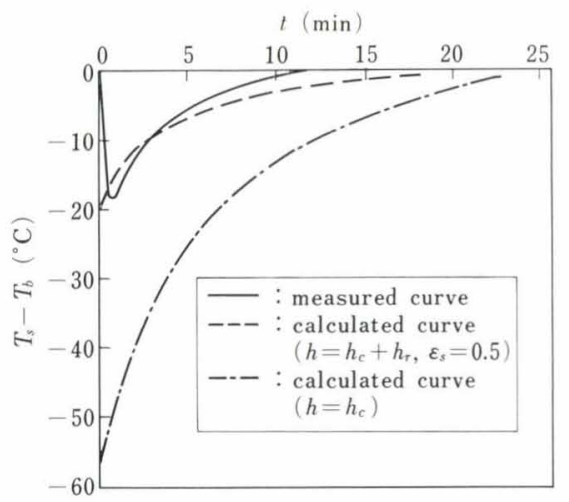

Fig. 10. Temperature change on the surface of pellet at the bulk gas temperature of $1023^{\circ} \mathrm{C} \quad\left(T_{b}=1023^{\circ} \mathrm{C}\right.$, $p_{\mathrm{H}_{2}}=1.0 \mathrm{~atm}, V=30 \mathrm{~N} l / \mathrm{min}, d_{p}=1.2 \mathrm{~cm}$ ) 


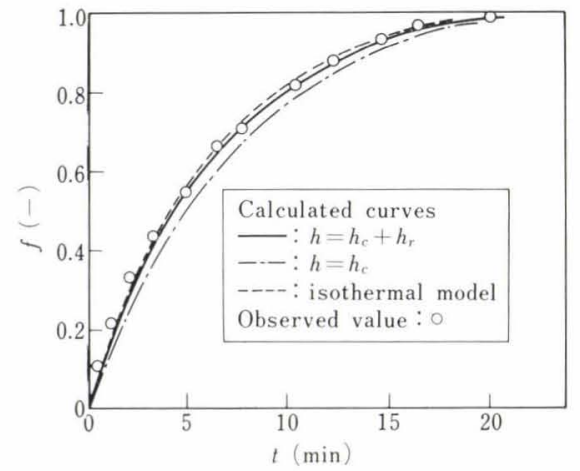

Fig. 11. Comparison of the calculated reduction curves with observed values $\quad\left(T_{b}=1023^{\circ} \mathrm{C}, \quad p_{\mathrm{H}_{2}}=\right.$ $1.0 \mathrm{~atm}, V=30 \mathrm{~N} l / \mathrm{min}, d_{p}=1.2 \mathrm{~cm}$ )

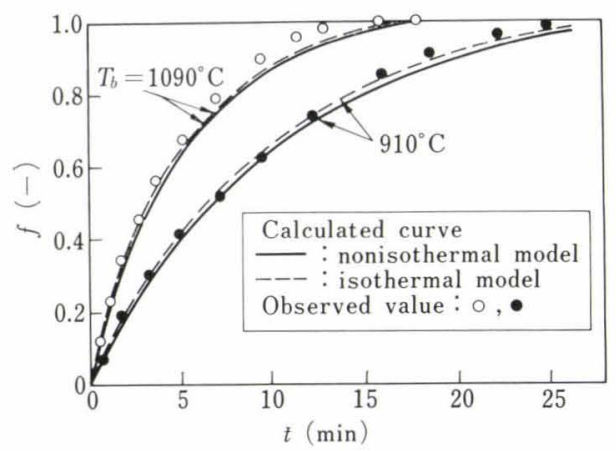

Fig. 12. Comparison of the calculated reduction curves with observed values $\left(p_{\mathrm{H}_{2}}=1.0 \mathrm{~atm}, V=30 \mathrm{~N} l / \mathrm{min}\right.$, $\left.d_{p}=1.2 \mathrm{~cm}\right)$

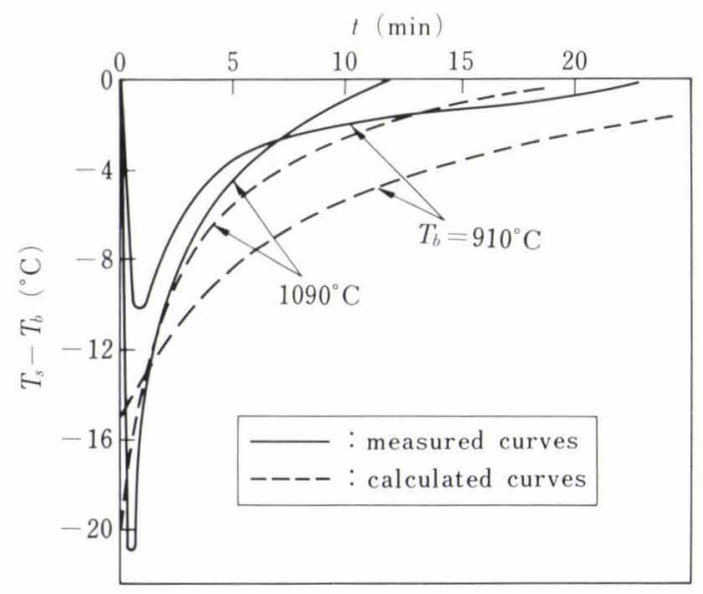

Fig. 13. Comparison of the calculated curves with measured curves in the surface temperature of a pellet $\left(p_{\mathrm{H}_{2}}=1.0 \mathrm{~atm}, \quad V=30 \mathrm{Nl} / \mathrm{min}, \quad d_{p}=1.2 \mathrm{~cm}\right)$

calculated curve based on the isothermal model was also shown in Fig. 11. The curve was scarcely different from the one based on the nonisothermal model including both convective and radiant heat transfer. While, the calculated curve with neglection of the radiant heat transfer slightly deviated from the measured values, but the difference in these reduction curves was smaller than that in the temperature change on the surface of a pellet.

Figures 12 and 13 show a comparison of the calculated curves with the measured values for fractional reduction and surface temperature of the pellet at other reducing temperature, respectively. In the former, it is clear that both calculated curves based on the nonisothermal and isothermal models agreed well with the measured values. In the latter, the patterns of temperature change on the surface of the pellet were similar to those of Fig. 10. It was shown that the measured value at the bulk gas temperature of $910^{\circ} \mathrm{C}$ was slightly higher than the calculated curve, but at the bulk gas temperature of $1090^{\circ} \mathrm{C}$, a good agreement was obtained. From the above results, the present nonisothermal reaction model was proved to explain the heat and mass transfer phenomena in the reduction of iron oxide pellet with hydrogen.

Finally, it is important to evaluate accurately the rate parameters in the nonisothermal model when the model is applied to the noncatalytic reaction. It is, however, quite difficult to determine directly the rate parameters from measured values under nonisothermal state. Thus, the authors want to obtain the rate parameters of mass transfer from the measured values under isothermal state.

Unfortunately, in the gas-solid noncatalytic reaction, complete isothermal condition could not be realized. However, almost isothermal condition will be attained by diluting the reducing gas with inert gas and by using the heating furnace which has a high heating capacity, because such dilution decreases the rate of heat absorption, on the other hand, high capacity furnace plays a role to decrease the temperature gradient between the surroundings and the reaction interface by supplying sufficient heat.

\section{Conclusion}

The reduction of a single iron oxide pellet with hydrogen was analysed by a nonisothermal model including the heat and mass transfer process. From this mathematical model, the fractional reduction and the surface temperature of the pellet were calculated. The theoretical results obtained agreed well with the experimental values.

Rate parameters, $k_{i}, D_{s}, k_{f}, k_{s}, h$, included in the nonisothermal model were determined as follows. The values of $k_{i}$ and $D_{s}$ were determined by the reaction analysis of the measured values according to the method of mixed control. While, the values of $k_{f}$, $k_{s}$, and $h$ were obtained from the empirical equations inserting the present experimental conditions. It was found from these parameters that the heat transfer by convection and radiation should be taken into consideration for the evaluation of ' $h$ '.

Heat and mass transfer processes between the surroundings and the pellet surface and those in the pellet were investigated. It was found that the overall heat transfer was governed by the heat transfer resistance between the surroundings and the pellet surface, while the mass transfer was mainly governed by the intraparticle diffusion and chemical reaction steps.

The surface temperature of a pellet changed by the maximum value of about $20^{\circ} \mathrm{C}$ and the interval in which temperature fell considerably was very short. On the other hand, the calculated fractional reduction, even though it is based on an isothermal model, agreed well with the measured one. However, the temperature change of a pellet can not be estimated by the isothermal model. The effect of the tempera- 
ture drop upon the fractional reduction was not so significant even in the rapid reduction with pure hydrogen. Therefore, the rate parameters of the mass transfer in the nonisothermal model for the reduction of a single iron oxide pellet with hydrogen might be determined with a sufficient accuracy by analysing the measured values on an assumption that the reaction would proceed isothermally. However, for evaluating the rate parameters of mass transfer, the experiment should be planned so that the reaction proceeds isothermally as far as possible by mixing inert gas to reducing gas.

\section{Nomenclature}

$C_{b}, C_{i}, C_{s}$ : concentration of reducing gas at bulk, at reaction interface, and at surface of pellet, respectively, $\mathrm{mol} \mathrm{H}_{2} / \mathrm{cm}^{3}$

$C_{b}^{*}, C_{i}^{*}$ : concentration of bulk gas and of reaction interface in equilibrium, respectively, mol $\mathrm{H}_{2} / \mathrm{cm}^{3}$

$c_{p}$ : $\quad$ specific heat of gas, cal $/ \mathrm{g} \cdot{ }^{\circ} \mathrm{K}$

$D$ : diffusion coefficient of reducing gas, $\mathrm{cm}^{2} /$ $\min$

$D_{s}$ : intraparticle diffusivity of reducing gas, $\mathrm{cm}^{2} / \mathrm{min}$

$D_{t}$ : inner diameter of reaction tube, $\mathrm{cm}$

$d_{p}$ : diameter of pellet, $\mathrm{cm}$

$E$ : activation energy, $\mathrm{cal} / \mathrm{mol} \mathrm{H}_{2}$

$F$ : relative distance of reduced layer, $\quad(=1-$ $\left.(1-f)^{1 / 3}\right)$

$f$ : fractional reduction

$\Delta H_{T i}^{\circ}$ : heat of reaction, $\mathrm{cal} / \mathrm{mol} \mathrm{H}_{2}$

$h$ : heat transfer coefficient between surroundings and pellet surface, cal $/ \mathrm{cm}^{2} \cdot \mathrm{min} \cdot{ }^{\circ} \mathrm{K}$

$h_{c}, h_{r}$ : heat transfer coefficient by convection and radiation, respectively, $\mathrm{cal} / \mathrm{cm}^{2} \cdot \mathrm{min} \cdot{ }^{\circ} \mathrm{K}$

$\kappa$ : equilibrium constant

$k_{i}, k_{b}$ : reaction rate constant at the temperature of reaction interface and of bulk gas, respectively, $\mathrm{cm} / \mathrm{min}$

$k_{\mathrm{Fe}}$ : thermal conductivity of pure iron, $\mathrm{cal} / \mathrm{cm}$. $\min \cdot{ }^{\circ} \mathrm{K}$

$k_{f}$ : mass transfer coefficient through gaseous film, cm $/ \mathrm{min}$

$k_{o}$ : frequency factor of reaction rate constant, $\mathrm{cm} / \mathrm{min}$

$k_{s}$ : thermal conductivity of reduced iron layer, $\mathrm{cal} / \mathrm{cm} \cdot \min \cdot{ }^{\circ} \mathrm{K}$

$k_{t}$ : thermal conductivity of reducing gas, $\mathrm{cal} / \mathrm{cm} \cdot \min \cdot{ }^{\circ} \mathrm{K}$

$M_{h}$ : molecular weight of $\mathrm{Fe}_{2} \mathrm{O}_{3}$

$\mathcal{N} u$ : Nusselt number $\left(=h d_{p} / k_{t}\right)$

Pr: Prandtle number $\left(=c_{p} \mu / k_{t}\right)$

$p_{\mathrm{H}_{2}}, p_{\mathrm{N}_{2}}$ : partial pressures of $\mathrm{H}_{2}$ and $\mathrm{N}_{2}$ gas, respectively, atm

$R$ : gas constant, cal $/ \mathrm{mol} \cdot{ }^{\circ} \mathrm{K}$

$R^{*}$ : rate of mass transfer, $\mathrm{mol} \mathrm{H}_{2} / \mathrm{min}$

$R_{h}^{*}$ : rate of heat transfer, cal $/ \mathrm{min}$

$R e_{p}:$ particle Reynolds number $\left(=d_{p} u \rho / \mu\right)$

$r$ : radial distance from the center of pellet, $\mathrm{cm}$

$r_{i}, r_{o}$ : radius of unreacted-core in pellet and radius of pellet, respectively, $\mathrm{cm}$
Sc: Schmidt number $(=\mu / \rho D)$

Sh: Sherwood number $\left(=k_{f} d_{p} / D\right)$

$T_{b}, T_{i}, T_{s}$ : temperatures of bulk gas, reaction interface, and surface of pellet, respectively, ${ }^{\circ} \mathrm{K}$

$t$ : reducing time, $\min$

$t_{f}$ : reducing time controlled by diffusion process through gaseous film, min

$u$ : linear velocity of gas, $\mathrm{cm} / \mathrm{min}$

$V$ : flow rate of gas, $\mathrm{N} l / \mathrm{min}$

$W$ : weight of a pellet, $\mathrm{g}$

$\varepsilon_{f}$ : porosity of reduced iron layer

$\varepsilon_{p}$ : initial porosity of pellet

$\varepsilon_{s}$ : emissivity of pellet

$\varepsilon_{t}$ : emissivity of reaction tube wall (assumed $\varepsilon_{t}=0.5$ )

$\varepsilon_{w}:$ porosity of wustite pellet

$\mu$ : viscosity of reducing gas, $\mathrm{g} / \mathrm{cm} \cdot \mathrm{min}$

$\xi$ : labyrinth factor

$\rho:$ density of reducing gas, $\mathrm{g} / \mathrm{cm}^{3}$

$\rho_{h}$ : apparent density of initial pellet, $\mathrm{g} / \mathrm{cm}^{3}$

$\rho_{w}$ : apparent density of wustite pellet, $\mathrm{g} / \mathrm{cm}^{3}$

\section{REFERENCES}

1) W. M. McKewan: Trans. Met. Soc. AIME, 218 (1960), 2.

2) L. von Bogdandy and W. Janke: Z. Electrochem., 61 (1957), 1146.

3) R. Takahashi, J. Yagi, and Y. Omori: SCI. REP. RITU, A 23 (1971), 9.

4) Y. Hara, M. Tsuchiya, and S. Kondo: Tetsu-to-Hagané, 55 (1969), 1297.

5) T. Yagi and Y. Ono: Trans. ISIJ, 8 (1968), 377.

6) R. H. Spitzer, F. S. Manning, and W. O. Philbrook: Trans. Met. Soc. AIME, 236 (1966), 726.

7) B. Seth and H. U. Ross: Trans. Met. Soc. AIME, 233 (1965), 180.

8) P. K. Strangway, S. Toppi, and H. U. Ross: Can. Met. Quart., 5 (1966), 211.

9) S. Kondo, Y. Hara, and M. Tsuchiya: Tetsu-to-Hagané, $\mathbf{5 6}$ (1970), S3.

10) J. Shen and J. M. Smith: I. and E.C. Fundamentals, 4 (1965), 293.

11) A. K. Lahiri: JISI, 206 (1968), 927.

12) W. E. Ranz and W. R. Marshall: Chem. Eng. Progr., 48 (1952), 141.

13) K. Sato: Chem. Eng., Japan, 28 (1964), 490.

14) C. R. Wilke: J. Chem. Phys., 18 (1950), 517.

15) W. Licht and D. G. Stechert: J. Phys. Chem., 48 (1944), 23.

16) O. Kubaschewski, E. LL. Evans, and C. B. Alcock: Metallurgical Thermochemistry, 4th Ed., (1967), Pergamon Press.

17) A. Moriyama, J. Yagi, and I. Muchi: Trans. ISIJ, 7 (1967), 271.

18) R. G. Olsson and W. M. McKewan: Trans. Met. Soc. AIME, 236 (1966), 1518.

19) Y. Hara, M. Sugata, T. Kaida, and S. Kondo: J. Japan Inst. Metals, 31 (1967), 207.

20) K. Shiba: Bussei-Teisuhyo, (1944), Iwanami Shoten, Tokyo, 184.

21) W. D. Kingery: Introduction to Ceramics, (1960), Wily, New York, 504.

22) J. Francl and W. D. Kingery: J. Am. Cer. Soc., 37 (1954), 99.

23) S. Sugiyama and M. Hasatani: Chem. Eng., Japan, 28 (1964), 355.

24) J. H. Perry, C. H. Chilton, and S. D. Kirkpatrick: Chemical Engineer's Handbook, (1953), McGraw-Hill, 3. 